Table. Peripheral blood cell counts for each week.

\begin{tabular}{|c|c|c|c|c|c|c|c|c|c|}
\hline & \multicolumn{3}{|c|}{ tofacitinib } & \multicolumn{6}{|c|}{ baricitinib } \\
\hline & week & LDA & $p$ & not LDA & $p$ & LDA & $p$ & not LDA & $p$ \\
\hline White Blood & 0 & $6821 \pm 2402$ & & $6041 \pm 2612$ & & $7994 \pm 4309$ & & $7886 \pm 2513$ & \\
\hline Cells & 4 & $6247 \pm 1905$ & 5.254 & $46465 \pm 2440$ & 0.344 & $46706 \pm 2499$ & 9.059 & $97143 \pm 1526$ & 5.363 \\
\hline \multirow{2}{*}[/\mul]{} & 12 & $6480 \pm 1949$ & 9.497 & $75871 \pm 2070$ & 0.217 & $76470 \pm 2867$ & 7.031 & $17383 \pm 2963$ & 3.356 \\
\hline & 24 & $6733 \pm 2297$ & 7.858 & $86450 \pm 3001$ & 1.428 & $86418 \pm 2875$ & 5.024 & $46833 \pm 1021$ & 1.454 \\
\hline Neutrophils & 0 & $4888 \pm 2399$ & & $3982 \pm 2300$ & & $6221 \pm 4085$ & & $6221 \pm 4085$ & \\
\hline \multirow{3}{*}[/\mu\mathrm{l}]{} & 4 & $4243 \pm 1655$ & 5.210 & $4298 \pm 2100$ & 0.461 & $14548 \pm 2578$ & 3. 015 & $55923 \pm 2716$ & 6.294 \\
\hline & 12 & $4261 \pm 1843$ & 3.324 & $43617 \pm 1869$ & 9.236 & $64542 \pm 3062$ & 2.019 & $95429 \pm 3055$ & 5.311 \\
\hline & 24 & $4487 \pm 2243$ & 3.657 & $74547 \pm 2847$ & 7.190 & 2900 & 0.008 & $84474 \pm 1396$ & .207 \\
\hline Lymphocytes & 0 & $1419 \pm 651$ & & $1305 \pm 489$ & & $1370 \pm 416$ & & $1395 \pm 485$ & \\
\hline \multirow[t]{3}{*}[/\mul]{} & 4 & $1515 \pm 544$ & .357 & $7 \quad 1502 \pm 514$ & .039 & $91730 \pm 659$ & .013 & $31530 \pm 652$ & .484 \\
\hline & 12 & $1537 \pm 555$ & .523 & $31327 \pm 664$ & .996 & $61569 \pm 572$ & .011 & $1 \quad 1453 \pm 401$ & .832 \\
\hline & 24 & $1511 \pm 598$ & .697 & $7 \quad 1143 \pm 378$ & .092 & $21792 \pm 699$ & .011 & $1836 \pm 710$ & .109 \\
\hline Platelets & 0 & $26.9 \pm 9.1$ & & $23.7 \pm 6.6$ & & $30.3 \pm 11.2$ & & $26.9 \pm 7.4$ & \\
\hline \multirow[t]{3}{*}[10^{4}/\mu\mathrm{l}]{} & 4 & $25.5 \pm 8.9$ & .291 & $23.8 \pm 6.6$ & .940 & $30.5 \pm 4.6$ & .940 & $27.3 \pm 10.8$ & .798 \\
\hline & 12 & $24.7 \pm 7.4$ & .261 & $25.6 \pm 7.5$ & .209 & $33.1 \pm 8.3$ & .209 & $927.0 \pm 9.3$ & .905 \\
\hline & 24 & $26.3 \pm 8.1$ & .930 & $23.3 \pm 6.1$ & .961 & $1 \quad 33.4 \pm 6.9$ & .961 & $1 \quad 33.0 \pm 4.4$ & .063 \\
\hline
\end{tabular}

Data are mean \pm standard deviation. LDA: patients achieved SDAI LDA at week 24. not LDA: patients did not achieve SDAI LDA at week 24. Shown $p$ values were calculated by t-test compared to week 0 .

Disclosure of Interests: None declared

DOI: 10.1136/annrheumdis-2020-eular.1468

\section{AB0359 TNF ALFA THERAPY AND RADIOSYNOVIORTHESIS IN PATIENTS WITH RHEUMATOID ARTHRITIS}

M. Szentesi ${ }^{1}$, Z. Nagy ${ }^{2}$, Z. Karoly Mangel ${ }^{1}$, G. Csőre ${ }^{3}$, P. Géher ${ }^{1} .{ }^{1}$ Polyclinic of the Hospitaller Brothers of St. John of God, Rheumatology, Budapest, Hungary; ${ }^{2}$ Polyclinic of the Hospitaller Brothers of St. John of God, Budapest, Hungary; ${ }^{3}$ St. Andrew Hospital for Rheumatic Diseases, Rheumatology, Hévíz, Hungary

Background: The treatment of patients with rheumatoid arthritis (RA) has been spectaculary changed since the 1950's. Introduction of the steroid compounds and their local application, the chemical and radionuclide synovectomy, surgical synovectomy, use of non steroid drugs, the basic treatment and the spread of biological therapy are the most important steps. Introduction of the biological therapy has changed the quality of life for these patients.

Objectives: During biological therapy sometimes 1 or 2 joints could be affected by inflammation. In this cases always the question is how to solve the problem. Change of the biological or basic therapy, use surgical synovectomy or radiosynovectomy (RSO)?

Methods: In our reumatological department 2100 patients with RA were treated with biological therapy between 2002 and 2018. In 100 patients we applied RSO because of the inflammation of the knee joint during biological therapy. We made a long term follow-up in 82 patient. All participants provided written informed consent. 82 participants inflammatory knee joint disease was diagnosed on the basis of the American College of Rheumatology. 70 of 82 patients with rheumatoid arthritis were seropositive, 12 seronegative. Steinbrocker functional stadium II was observed in 72 , stadium III in 10. Mean age of 18 male and 76 female patients was 51.4 years (range 24-79) years. In 42 patients the right knee, in 40 the left knee was treated by radiosynovectomy. Mean duration of disease was 8.3 years (range $0.5-25$ ), of synovitis (6.3month (range 3-8) Mean number of punctions of the treated joint prior to radiosynovectomy was 4,2 per patient and of steroid administrations prior to radiosynovectomy 3,0 . In 15 patients a systemic steroid therapy has been performed. Results: During the study period, inflammation decreased. In the first 3 years excellent and good results were recorded in $81,2 \% .3$ years after radiosynoviorthesis $82.2 \%$ of patients did not need another punction.

Before the knee inflammation patients were in complete remission which status has been achieved after RSO as well. DAS: 2,4+-0,4.

Conclusion:

1. RSO is an effective method to treat the inflammation of the knees.

2. The RSO performed during biological tehrapy is as effective as in the case of patients without biological therapy.

3. In case of a successful RSO there is no need for biological or basic therapy neither for surgical synovectomy.

4. However an intraarticular injection has a low risk for infection it is recommended to avoid the biological therapy during the RSO.

\section{References:}

[1] WHO Scientific Group, 2003

[2] Szekanecz Z.: Célzott terápia a reumatológiában. Klinikum és Tudomány, MOTESZ Magazin; 2010;XVIII(2):31-44.

[3] Mclnnes IB, Schett G. Cytokines in the pathogenesis of rheumatoid arthritis. Nat Rev Immunol. 2007 Jun;7(6):429-42
[4] Klippel JH. Primer on the Rheumatic Disease. 12th ed. 2001.

[5] Lipsky PE. Harrison's Principles of Internal Medicine. 16th ed. 2005

[6] EULAR recommendations for the management of rheumatoid arthritis with synthetic and biological disease-modifying antirheumatic drugs: 2013 update

[7] Fellinger K. and Schmid J.: Die lokale Behandlung der rheumatischen Erkrankungen. Z. Inn. Med. 33. 351. 1952.

[8] Watanabe M., Takeda S., Ikeuchi H.: Atlas of arthroscopy 2nd ed. Tokyo: Igaku Shoin 1969.

[9] Stucki G., Bozzone P., Treuer E., Wassmer P. and Felder M.: Efficacy and safety of radiation synovectomy with Yttrium-90: A retrospective long term analysis of 164 applications in 82 patients. British J. of Rheumatology 32. 5. 383-386. 1993.

[10] Combe B., Krause E. and Sany J.: Treatment of chronic knee synovitis with arthroscopic synovectomy after failure of intra-articular injection of radionuclide. Arthritis Rheum. 32. 1. 10-14. 1989.

Disclosure of Interests: None declared

DOI: 10.1136/annrheumdis-2020-eular.587

\section{AB0360 1 EFFICACY AND SAFETY OF THE PROSTAGLANDIN EP4 RECEPTOR ANTAGONIST CR6086 ADDED TO METHOTREXATE IN DMARD-NAÏVE EARLY RA PATIENTS: A PHASE 2 RANDOMIZED CONTROLLED TRIAL}

K. Pavelka ${ }^{1}$, I. D. Delina ${ }^{2}$, M. Mazur ${ }^{3}$, M. D'amato ${ }^{4}$, G. Giacovelli ${ }^{4}$, F. Girolami ${ }^{4}$ M. Krogulec ${ }^{5}$, R. Østgård ${ }^{6}$, A. R. Bihlet ${ }^{7}$, O. Kubassova ${ }^{8}$, L. Rovati ${ }^{4,9}$, P. C. Taylor ${ }^{10} .{ }^{1}$ Institute of Rheumatology, Prague, Czech Republic; ${ }^{2}$ Diagn. Consult. Center Aleksandrovska EOOD, Sofia, Bulgaria; ${ }^{3}$ Nicolae Testemitanu State Univ. of Med. and Pharm., Chisinau, Moldova, Republic of; ${ }^{4}$ Rottapharm Biotech, Monza, Italy; ${ }^{5}$ NZOZ Lecznica MAK-MED, Nadarzyn, Poland;

${ }^{6}$ Silkeborg Regional Hospital, Silkeborg, Denmark; ${ }^{7}$ Nordic Bioscience, Herlev Denmark; ${ }^{8}$ Image Analysis Group, London, United Kingdom; ${ }^{9}$ Univ. of Milano Bicocca, Milano, Italy; ${ }^{10}$ Botnar Research Center, Univ. of Oxford, Oxford, United Kingdom

Background: MTX is the first line treatment in early RA. There is robust evidence from cohort studies, but less from RCTs, that a "window of opportunity" exists over 12-16 weeks symptom duration. CR6086 is a selective prostaglandin EP4 receptor antagonist, with an immunomodulatory profile.

Objectives: To test efficacy and safety of CR6086 added to MTX in early RA DMARD-naïve patients.

Methods: Patients with RA (ACR/EULAR 2010 criteria),$<1$ year from symptom onset and naïve to DMARDs were randomized to oral CR6086 30, 90, 180mg, or placebo bid and oral MTX (20mg weekly) for 13 weeks (NCT03163966). Primary endpoint was the ACR20 response rate: 240 patients were needed to detect a difference among groups, with $50 \%$ responders on placebo and $70 \%$ on the $90 \mathrm{mg}$ CR6086 target dose. Pairwise comparisons of proportions were performed, with nonresponder imputation for withdrawals. A subgroup of patients underwent dynamic contrast-enhanced (DCE) MRI for quantification of synovitis at MCP and wrist joints, evaluated as DEMRIQ-ME and DEMRIQ-vol.

Results: The ITT population included all 244 randomized patients receiving at least one dose of study drugs (59 CR6086 30mg/MTX, 60 CR6086 90mg/MTX 63 CR6086 180mg/MTX, 62 placebo/MTX). Safety was good with no increased rate of infections or other disorders; however, there were more minor upper GI adverse events (AEs) with CR6086, and increased dropouts due to AEs with the $180 \mathrm{mg}$ dose $(9 / 63,14.3 \%$ vs $1.7-3.4 \%$ in other groups). There were more ACR20 responders with MTX monotherapy than predicted $(59.7 \%)$ and thus the $10.3 \%$ difference with the $90 \mathrm{mg}$ target dose $(70.0 \%)$ was not significant. The low $30 \mathrm{mg}$ dose was no better than placebo $(55.9 \%)$, while the high $180 \mathrm{mg}$ dose did not provide additional benefit compared with $90 \mathrm{mg}$ (74.0\% net of dropouts). CR6086 90mg and 180mg induced a significant improvement in MRI, compared with placebo (Fig. 1). In a post-hoc analysis in patients 6 months from symptom onset (ACR definition of early RA: 98/244, 40.2\%), MTX monotherapy exerted a large $76 \%$ ACR20 response rate that precluded potentiation. Conversely, in patients of 6-12 months disease duration (146/244 $59.8 \%$ ) ACR20 responders were $48.6 \%$ with MTX monotherapy vs $68.4 \%$ with $90 \mathrm{mg}$, i.e. a $19.8 \%$ difference as postulated, with proportional differences in secondary endpoints (Tab. 1).

Conclusion: There was no benefit demonstrated for CR6086 added to MTX in the study cohort as a whole. However, in a post-hoc analysis, enhanced responses were observed with CR6086 90mg bid added to MTX in patients $>6$ months disease duration. This generated the hypothesis that addition of CR6086 $90 \mathrm{mg}$ bid may benefit in RA patients initiating MTX after the window of opportunity, to be tested in further studies. 
Table 1. ITT outcomes at week 13

\begin{tabular}{|c|c|c|c|c|}
\hline & $\begin{array}{c}\text { Symptom onset }<12 \\
\text { months } \\
\text { (principal analysis) }\end{array}$ & & $\begin{array}{c}\text { Symptom onset 6-12 } \\
\text { months } \\
\text { (post-hoc analysis)* }^{*}\end{array}$ & \\
\hline & $\begin{array}{l}\text { Placebo } \\
+\mathrm{MTX} \\
(\mathrm{N}=62)\end{array}$ & $\begin{array}{l}\text { CR6086 } \\
90 \mathrm{mg} \\
+\mathrm{MTX} \\
(\mathrm{N}=60)\end{array}$ & $\begin{array}{l}\text { Placebo } \\
+\mathrm{MTX} \\
(\mathrm{N}=37)\end{array}$ & $\begin{array}{c}\text { CR6086 } \\
90 \mathrm{mg} \\
+\mathrm{MTX} \\
(\mathrm{N}=38)\end{array}$ \\
\hline ACR20, \% & $59.7 \%$ & $70.0 \%$ & $48.6 \%$ & $68.4 \%$ \\
\hline ACR50, \% & $33.9 \%$ & $38.3 \%$ & $29.7 \%$ & $39.5 \%$ \\
\hline ACR70, \% & $17.7 \%$ & $23.3 \%$ & $10.8 \%$ & $28.9 \%$ \\
\hline DAS28 (CRP) $<2.6, \%$ & $12.9 \%$ & $20.0 \%$ & $8.1 \%$ & $18.4 \%$ \\
\hline $\mathrm{CDAI} \leq 2.8, \%$ & $8.1 \%$ & $11.7 \%$ & $5.4 \%$ & $15.8 \%$ \\
\hline SDAI $\leq 3.3, \%$ & $6.5 \%$ & $10.0 \%$ & $2.7 \%$ & $15.8 \%$ \\
\hline $\begin{array}{l}\text { Boolean-based remis- } \\
\text { sion, \% }\end{array}$ & $6.5 \%$ & $6.7 \%$ & $2.7 \%$ & $10.5 \%$ \\
\hline
\end{tabular}

*In patients with symptom onset $<6$ months, MTX monotherapy exerted a large $76 \%$ ACR20 response, and correspondingly high secondary efficacy parameters, precluding potentiation in this subset

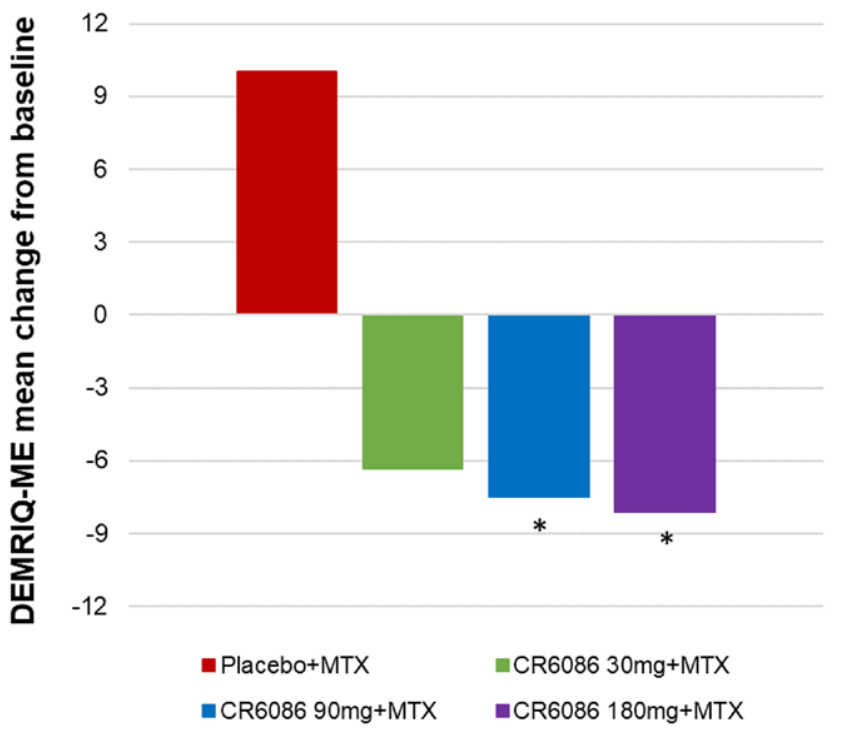

${ }^{*} \mathrm{p} \leq 0.05$ between CR6086+MTX group and Placebo+MTX group

\# DEMRIQ-vol showed a similar pattern

Figure 1. Change in MRI (DEMRIQ-ME") after 13 weeks

Disclosure of Interests: Karel Pavelka Consultant of: Abbvie, MSD, BMS, Egis, Roche, UCB, Medac, Pfizer, Biogen, Speakers bureau: Abbvie, MSD, BMS, Egis, Roche, UCB, Medac, Pfizer, Biogen, Ivanova Delina2 Delina: None declared, Minodora Mazur: None declared, Massimo D’Amato Employee of: Rottapharm Biotech, GIAMPAOLO GIACOVELLI Employee of: Rottapharm Biotech, Federica Girolami Employee of: Rottapharm Biotech, Marek Krogulec: None declared, René Østgård: None declared, Asger Reinstrup Bihlet Shareholder of: Nordic Bioscience A/S., Olga Kubassova Shareholder of: IAG, Image Analysis Group, Consultant of: Novartis, Takeda, Lilly, Employee of: IAG, Image Analysis Group, Lucio Rovati Shareholder of: Rottapharm Biotech, Employee of: Rottapharm Biotech, Peter C. Taylor Grant/research support from: Celgene, Eli Lilly and Company, Galapagos, and Gilead, Consultant of: AbbVie, Biogen, Eli Lilly and Company, Fresenius, Galapagos, Gilead, GlaxoSmithKline, Janssen, Nordic Pharma, Pfizer Roche, and UCB DOI: 10.1136/annrheumdis-2020-eular.5636

\section{AB0361 EFFICACY AND SAFETY OF BARICITINIB (BARI) IN RHEUMATOID ARTHRITIS(RA): CLINICAL AND ULTRASOUND EVALUATION IN REAL LIFE}

G. Tesei ${ }^{1}$, C. Bruni ${ }^{1}$, L. Cometi ${ }^{1}$, F. Nacci ${ }^{1}$, M. Capassoni ${ }^{1}$, R. Terenzi ${ }^{1}$, L. Tofani ${ }^{1}$, F. Bartoli ${ }^{2}$, G. Fiori ${ }^{2}$, M. Matucci-Cerinic ${ }^{1,2} .{ }^{1}$ University of Florence,

Faculty of Medicine, Experimental and Clinical Medicine, Division of Rheumatology, Firenze, Italy; ${ }^{2}$ Careggi University Hospital, Rheumatology, Firenze, Italy

Background: Remission or low disease activity (LDA) are the ultimate goals of both conventional synthetic (csDMARD), target synthetic and biologic disease-modifying anti-rheumatic drugs (bDMARD) in treating RA. Janus Kinase (JAK) inhibitors are nowadays part of tsDMARDs, with BARI as an oral selective JAK1-2 inhibitor. Ultrasound (US) is a valuable imaging tool for detecting inflammatory joint changes and monitoring RA patients. The US7 score (US7) is a semiquantitative score including grayscale (GS) and power Doppler (PD) measurements of synovitis and tenosynovitis in 7 joints of the clinically dominant hand and foot.

Objectives: to evaluate real life efficacy and safety of BARI $4 \mathrm{mg}$ in RA patients using clinical, clinimetric and US evaluation.

Methods: adult RA patients starting BARI were eligible. DAS28ESR, CDAI, SDAI, painVAS, HAQ, COCHIN, laboratory parameters and US7 were performed/collected at baseline (BL) and after 3 and 6 months. Adverse events $(A E)$ and concomitant medications were recorded. Responder/non responder status was determined using DAS28ESR improvement according to the EULAR Response Criteria at 3 months. Moreover, SDAI clinical remission or LDA (remission: SDAI $\leq 3,3$; LDA:3,3<SDAI $\leq 11)$ were calculated at 3 and 6 months.

Results: 43 patients ( 12 csDMARD and 31 bDMARD failure) were enrolled, with 30 patients starting BARI in combination with a csDMARDs. BL painVAS was $68 \pm 23 \mathrm{~mm}$ and disease activity was moderate to severe according to DAS28VES CDAI and SDAI. BARI determined a significant improvement of every disease activity composite score and US7 components, except tendon PD; steroid daily dosage was significantly reduced.

28 patients were considered Responders at 3 months: responders used to have higher disease activity levels and synovitis scores at baseline.

Interestingly, painVAS and steroid dosage significantly decreased both in responders and non-responders, achieving similar value at 6 months. Non-responders showed both synovial and tendon involvement relapse at 6 months with significantly higher PD score compared to responders. Remission was reached by $12,8 \%$ patients at 3 months and $21,6 \%$ at 6 months, while LDA patients were respectively $53,8 \%$ and $51,3 \%$; combination with csDMARD was the only factor positively associated with remission/LDA at 3 months.

The percentage of dropped-out patients due to $A E$ was aligned with literature data ( $5 \%$ in 6 months) whereas the percentage of Herpes Zoster Virus (HZV) infections was higher (4,6\% in 6 months in our population vs $4,3 \%$ in 1 year in RCTs). Corticosteroid dosage was directly associated with $A E$ development at 6 months. Conclusion: Real life data confirmed BARI RCTs efficacy and safety data. Non responders showed both synovial and tendon PD disease relapse, despite painVAS and steroid reduction were comparable to responders. In our population, $\mathrm{HZV}$ infection prevalence was higher than in RCTs and corticosteroid dosage was positively associated with AE development at 6 months.

\begin{tabular}{|c|c|c|c|c|c|c|c|c|}
\hline & \multicolumn{2}{|c|}{ BL } & \multicolumn{2}{|c|}{$3 \mathrm{M}$} & \multirow[t]{2}{*}{$p$ value } & \multicolumn{2}{|c|}{$6 \mathrm{M}$} & \multirow[t]{2}{*}{$\mathrm{p}$ value } \\
\hline & $\mathbf{R}$ & NR & $\mathbf{R}$ & NR & & $\mathbf{R}$ & NR & \\
\hline painVAS & $67,88 \pm 23,37$ & $58,18 \pm 22,72$ & $30,19 \pm 23,52$ & $45,64 \pm 25,48$ & $\mathrm{p}=0.0040$ & $30,19 \pm 20,42$ & $29,73 \pm 22,15$ & $p=0.2105$ \\
\hline Daily prednisone equivalent & $5,97 \pm 5,57$ & $5,45 \pm 4,30$ & $2,96 \pm 3,02$ & $3,95 \pm 3,63$ & $\mathrm{p}=0.2248$ & $1,63 \pm 2,10$ & $3,03 \pm 3,59$ & $\mathrm{p}=0.1247$ \\
\hline GSS & $8,50 \pm 5,25$ & $7,00 \pm 3,81$ & $3,69 \pm 3,63$ & $2,33 \pm 2,45$ & $\mathrm{p}=0.9334$ & $3,56 \pm 3,01$ & $4,22 \pm 2,64$ & $\mathrm{p}=0.2452$ \\
\hline GST & $2,88 \pm 2,33$ & $3,11 \pm 2,09$ & $0,88 \pm 0,89$ & $1,56 \pm 1,59$ & $\mathrm{p}=0.6501$ & $1,00 \pm 1,37$ & $2,78 \pm 1,72$ & $\mathrm{p}=0.0831$ \\
\hline PDS & $8,00 \pm 7,11$ & $3,33 \pm 3,46$ & $3,00 \pm 3,48$ & $2,44 \pm 3,36$ & $p=0.0066$ & $3,25 \pm 3,13$ & $5,00 \pm 4,56$ & $p=0,0006$ \\
\hline PDT & $2,81 \pm 2,46$ & $2,44 \pm 3,36$ & $0,88 \pm 1,54$ & $1,33 \pm 1,50$ & $\mathrm{p}=0.44990$ & $1,06 \pm 1,53$ & $3,78 \pm 3,19$ & $\mathrm{p}=0.0156$ \\
\hline Erosions & $1,25 \pm 2,05$ & $0,44 \pm 0,73$ & $1,50 \pm 2,03$ & $0,44 \pm 0,73$ & $\mathrm{p}=0.0736$ & $1,31 \pm 2,09$ & $1,11 \pm 1,27$ & $\mathrm{p}=0.0902$ \\
\hline
\end{tabular}

